\title{
A AUSÊnCIA do SOM E A PERFORMANCE DO CORPO: \\ CRIAÇÃO DE RITMO NOS POEMAS EM LÍNGUA BRASILEIRA DE SINAIS
}

The absence of sound and the body performance: creating rhythm in poems in the brazilian sign language

Nayara Piovesan RIBEIRO

UFMT

nah_piovesan@hotmail.com

Vinícius Carvalho PEREIRA ${ }^{17}$

UFMT

viniciuscarpe@gmail.com

Fábio Vieira de SOUZA JÚNIOR ${ }^{18}$

UFMT

fabiovieirajunior@hotmail.com

RESUMO: Este artigo analisa o poema "Cinco sentidos", tradução para a Língua Brasileira de Sinais feita pelo artista surdo Nelson Pimenta, a partir do poema "Five Senses", originalmente produzido pelo também surdo Paul Scott, na British Sign Language. Nosso objetivo é identificar como se constituem elementos da camada fônica, tais quais o ritmo e a rima, em poemas surdos. Para tanto, revisitamos alguns conceitos de poesia, poema, ritmo e rima, originalmente pensados para línguas orais, a fim de verificar como esses se

${ }^{16}$ Mestranda do Programa de Pós-Graduação em Estudos da Linguagem, na área de concentração em Estudos Literários, da UFMT.

${ }^{17}$ Doutor em Ciência da Literatura pela UFRJ. Docente do Departamento de Letras e do Programa de Pós-Graduação em Estudos da Linguagem, da UFMT.

${ }^{18}$ Mestrando do Programa de Pós-Graduação em Estudos da Linguagem, na área de concentração em Estudos Linguísticos, na UFMT. Docente do Departamento de Letras, da UFMT.

Revista TextoPoético | ISSN: 1808-5385 | Vol. 21 (2o sem-2016) - p. 93. 
aplicam a produções poéticas em uma língua visuo-gestual. Como metodologia para a análise do poema, procedemos à leitura detalhada do poema gravado em vídeo, à transcrição do poema por meio de glosas e à análise dos elementos semióticos que constituem ritmo e rima no poema, com base no vídeo e nas glosas por nós elaboradas.

Palavras-chave: Poesia Surda. Ritmo. Rima. Poemas em Língua Brasileira de Sinais.

ABSTRACT: This paper analyzes the poem "Cinco sentidos", translated to the Brazilian Sign Language by the deaf poet Nelson Pimenta based on the poem "Five Senses", originally produced by the deaf poet Paul Scott, in the British Sign Language. Our goal is to identify the configuration of elements from the phonic layer, such as rhythm and rhyming, in deaf poems. To do so, we discuss some concepts of poetry, poem, rhythm and rhyme, originally created for oral languages, so as to verify to what extent those concepts make sense in poetic productions of a visual-spatial language. In terms of methodology, we read the poem in the video and transcribed it by means of glosses. Then, we analyzed the semiotic elements that constitute rhythm and rhyme in the poem, based on the video and the glosses we elaborated.

Keywords: Deaf Poetry. Rhythm. Rhyme. Poems in the Brazilian Sign Language.

\section{Introdução}

Ao falarmos e pensarmos em poesia surda e/ou em poemas surdos, logo nos vem o questionamento: em que medida se pode podem tomar produções tão recentes e tão diferentes do cânone da poesia ocidental como literatura e, mais ainda, como poemas? Temos, então, primeiramente a missão de tentar desconstruir para, posteriormente, reconstruir o termo Literatura e os critérios de inclusão, para considerar se essas obras em línguas de sinais podem ser chamadas ou não de poemas.

Devemos entender primeiramente o contexto em que se realizam os ainda incipientes estudos sobre a poesia em Libras: a Revista TextoPoético | ISSN: 1808-5385 | Vol. 21 (2o sem-2016) - p. 94. 
área da literatura surda. Segundo Klamt (2014), a literatura surda é uma literatura produzida por surdos, seja em língua de sinais, em línguas orais escritas (do mesmo modo como a maior parte da literatura ocidental), ou ainda pelo sistema de escrita de sinais conhecido por sign writing. A literatura surda inclui a literatura escrita sobre surdos, a literatura produzida por surdos e a literatura em língua de sinais, tendo como principal tema as vivências e experiências de pessoas surdas, e como público alvo os sujeitos surdos. A circulação dessa literatura dá-se através de livros, quando escrita em línguas orais (como o português, no caso dos surdos brasileiros) ou sign writing, e através de vídeos em sites da internet, quando produzidos na língua brasileira de sinais (Libras).

Trata-se, pois, de uma literatura que resgata "a memória das vivências surdas através das várias gerações dos povos surdos" (ROSA, 2006, p. 61). As produções literárias surdas são carregadas de características dessa identidade que se apresentam em diferentes gêneros, muitos dos quais também existem na cultura e literatura ouvintes, como poemas, piadas, contos de fadas, romances e lendas. Note-se, porém, que o que tem definido a literatura surda atualmente não é necessariamente a língua em que ela é produzida, que varia das performances aos registros escritos. $\mathrm{O}$ que tem de fato definido a literatura surda é o seu conteúdo e o impacto desse conteúdo nos sujeitos surdos, como instrumento de empoderamento de uma cultura marginalizada e oprimida. No entanto, pouco se sabe ou se publica nos meios acadêmicos sobre aspectos formais da poética surda.

Desse modo, ao longo deste artigo, evitaremos o uso do termo "Literatura Surda", por questões epistemológicas, uma vez que não analisamos ou destacamos as representações culturais atreladas às

Revista TextoPoético | ISSN: 1808-5385 | Vol. 21 (2o sem-2016) - p. 95. 
produções em língua brasileira de sinais. Dá-se preferência aqui, então, à denominação "literatura em Libras", ou mais especificamente "poesia em Libras", a fim de ressaltar o código em que essa literatura é produzida e elementos que subsidiam esta análise sobretudo imanentista. É importante, porém, ressaltar que não estamos tentando negar, negligenciar ou ainda diminuir o fato de a literatura produzida em língua de sinais estar diretamente relacionada à cultura do povo surdo. $\mathrm{O}$ intento da pesquisa é analisar essas produções literárias a partir da língua em que são constituídas, porém isso "não significa que se deva ignorar o peso de uma literatura que espelha os discursos correntes ou as modas culturais, pois é preciso reconhecer o sim e o não em todas as coisas" (BOSI, 2000. p. 15).

Sabemos que não há como comparar duas línguas com configurações e estruturas diferentes, visto que as línguas orais, como o Português, são oral-auditivas, enquanto as línguas de sinais são visuo-espaciais. Porém, neste primeiro momento de estudo e pesquisa, dada a necessidade de uma base teórica minimamente consolidada para o desenvolvimento da argumentação, partiremos dos conceitos dos efeitos sonoros na poesia escrita de línguas orais para análise de um poema em língua de sinais. Para tal, conceituaremos ritmo e rima nas línguas orais a partir de estudos de Goldstein (2005), Paz (1982), Brik (1979), e em língua de sinais a partir dos estudos de Valli (1993), Sutton-Spence (2005), Porto (2011) e Klamt (2014). Em seguida, analisaremos, segundo esses conceitos, o poema "Cinco sentidos", artista surdo Nelson Pimenta, a partir do poema "Five Senses",20, originalmente produzido pelo também surdo Paul Scott, na British Sign

${ }^{19}$ O poema "Cinco Sentidos", analisado neste artigo, pode ser encontrado no link $<$ https://www.youtube.com/watch? $\mathrm{v}=\mathrm{xmOnY1B2jEI}>$

20 A versão original do poema "Five Senses" pode ser encontrada no link $<$ https://www.youtube.com/watch?v=QrOEQf2O918>.

Revista TextoPoético | ISSN: 1808-5385 | Vol. 21 (2o sem-2016) - p. 96. 
Language. Para fins de clareza, cabe aqui ressaltar que se trata de poemas em vídeo, compostos como performance visuo-gestual, e não como transposição de poemas originalmente escritos em linguagem fonética sobre uma página, uma tela, ou superfície que o valha. Assim, sugerimos aos leitores do artigo não familiarizados com as línguas de sinais o procedimento mais comum para recepção dessas obras: inicialmente, assistir, a partir dos links registrados em nota de rodapé, aos vídeos em que as performances são registradas, e em seguida acompanhar a análise literária a partir da glosa disponibilizada mais à frente neste artigo.

Vale ainda ressaltar que não abordaremos aqui questões referentes aos processos de tradução interlingual, uma vez que estamos considerando a obra traduzida por Nelson Pimenta como o poema em si a ser analisado. Ademais, não negligenciamos nossa condição de ouvintes nesta análise da poesia surda, na medida em que o etos, ou o horizonte de expectativa do leitor, acaba por definir, ou pelo menos influenciar, as possibilidades interpretativas a que se tem acesso. Trata-se, pois, de uma proposta de leitura entre as várias outras que ouvintes ou surdos poderiam construir.

\section{Conceituando poema}

Ao longo dos anos, nos estudos que envolvem a lírica, sua formação e seu processo de construção, muitos pesquisadores da área, e aqui destacamos os estudos da estilística do som, buscaram investigar a criação dos efeitos de sonoridade produzidos pelo texto poético, tendo em vista a máxima de que "toda poesia aspira a se fazer voz; a se fazer, um dia, ouvir" (ZUMTHOR, 2010 apud ROSA; CAMARGO, 2013, p. 206). Na tradição escrita, normalmente os poemas são compostos pela organização topográfica no papel do

Revista TextoPoético | ISSN: 1808-5385 | Vol. 21 (2o sem-2016) - p. 97. 
tecido sonoro que compõe o texto, o que determina o ritmo e, consequentemente, constrói melodicamente o tom do poema (GOLDSTEIN, 2005). Portanto, diante dos estudiosos ou ainda do senso comum, diremos que o poema é, entre tantas outras coisas, uma união entre som e sentido, "a voz do povo, língua dos escolhidos, palavra do solitário" (PAZ, 1982, p. 21). Assim, tradicionalmente se concebe o poema como um instrumento de libertação das amarras sintáticas, semânticas e fônicas a que o discurso prosaico submete as palavras: "A palavra, finalmente em liberdade, mostra todas as suas vísceras, todos os seus sentidos e alusões, como um fruto amadurecido ou como os fogos de artifício no momento que explodem no céu. $\mathrm{O}$ poeta põe sua matéria em liberdade" (PAZ, 1982, p. 31).

Contudo, se a linguagem poética transpassa as fronteiras da língua, é dentro da própria língua que ela o faz (BARTHES, 1977). Em um poema, faz-se uso de mecanismos e estruturas presentes no sistema linguístico, mesmo que para transgredi-los, mas sem jamais ignorá-los. "Em suma, o artista não se serve dos seus instrumentos pedras, som, cor ou palavra - como o artesão, mas a eles serve para que recuperem sua natureza original. Servo da linguagem, seja ela qual for, o artista a transcende" (PAZ, 1982, p. 31)

Segundo Barthes (1977), a literatura é intransitiva, pois não fala sobre nada que não seja ela mesma. É apenas um jogo infinito da língua com a própria língua: não é luta, não é construção de identidade, não é ideologia - é tão-somente, enquanto jogo, uma trapaça da própria língua. Se pensarmos na poesia surda, é exatamente isso que temos: uma trapaça da língua para se fazer literatura, desfazendo o conceito arraigado de poesia baseada no primado do som.

Revista TextoPoético | ISSN: 1808-5385 | Vol. 21 (2o sem-2016) - p. 98. 
Para esta análise, partimos então do pressuposto de que não podemos dizer que uma obra é ou não um poema partindo apenas do pressuposto de sua estrutura organizacional sonora. Desse modo, a proposta aqui é mostrar que conceitos usados ao longo dos séculos para estudar a lírica podem ser empregados - nesse primeiro momento de análise - também na leitura de poemas em Libras, haja vista entendermos que os efeitos chamados fônicos ${ }^{21}$ podem se apresentar de várias maneiras que não somente através dos sons, como será visto na próxima seção, em que utilizaremos o termo poema para as produções literárias poéticas produzidas em Língua Brasileira de Sinais.

\section{Ritmo e rima nos poemas em Língua Brasileira de Sinais}

Para estudar a questão de ritmo e rima na poesia em língua de sinais, é importante antes de mais nada abordarmos esses conceitos na poesia em línguas orais-auditivas. Segundo Goldstein (2005), toda e qualquer atividade humana se desenvolve dentro de um certo ritmo. Com isso, o ritmo aparece também nas produções artísticas criadas pelo homem, em especial, na poesia. De acordo com Goldstein (2005), o ritmo nos poemas é construído através da alternância de sílabas fortes e sílabas fracas, ou ainda entre sílabas formadas por vogais longas ou breves. Ainda segundo a autora, além da alternância entre as sílabas fortes e as fracas, temos como elementos rítmicos a repetição de sons e de palavras, desencadeando

\footnotetext{
${ }^{21}$ Mantivemos a terminologia de "camada fồnica" e "elementos fônicos" para análise da poesia em Libras uma vez que os estudos linguísticos da língua brasileira de sinais mantêm a nomenclatura de fonética ou fonologia para o estudo de parâmetros formacionais dos sinais.
}

Revista TextoPoético | ISSN: 1808-5385 | Vol. 21 (2o sem-2016) - p. 99. 
efeitos sonoros conhecidos como aliterações, assonâncias, anáforas e onomatopeias.

Segundo Brik (1979, p. 132), "devemos distinguir rigorosamente o movimento e o resultado do movimento". Segundo ele, um livro, um poema impresso no papel, nada mais é que o resultado do movimento e não o movimento em si, ou seja, o ritmo não pode ser capturado, mensurado, distinguido pelo texto impresso, pois esse suporte oferece tão-somente traços do movimento e não o movimento em si. Tal movimento, enquanto ato, existe também, senão exclusivamente, na declamação, na performance do poema. "Somente o discurso poético e não o seu resultado gráfico pode ser apresentado como um ritmo" (BRIK, 1979, p. 132). Com essa afirmação, podemos então chegar à conclusão de que o ritmo não é elemento presente apenas nos poemas de línguas orais-auditivas, por sua materialidade escrita, pois, como nos revela Brik, não é o resultado gráfico dos poemas que imprime a marca de ritmo ao mesmo, mas sim o ato de declamá-lo - o qual é uma constante em poemas em línguas visuo-espaciais, em que o movimento do poeta - suas mãos, sua face, seu corpo - inscreve ritmicamente o poema no ar.

Apesar de não haver, nas línguas de sinais, paralelos exatos a conceitos como ritmo, temos outros elementos da organização formacional na criação dos sinais que lhes conferem efeitos rítmicos no discurso, sobretudo no parâmetro formacional ${ }^{22}$ do movimento.

22 Segundo Brito (2010) e Karnopp e Quadros (2004), todos os sinais na Libras são compostos segundo cinco parâmetros formacionais: configuração de mão (posição que a mão assume ao realizar cada sinal), movimento (sequência de deslocamentos), ponto de articulação (onde a mão configurada se movimenta no espaço ou incide em alguma parte do corpo), orientação ou direção (para onde o sinal será conduzido) e as

Revista TextoPoético | ISSN: 1808-5385 | Vol. 21 (2o sem-2016) - p. 100. 
Segundo Valli (1993 apud PORTO, 2011) e Sutton-Spence (2005, p. 44 apud PORTO, 2011), o ritmo em língua de sinais é criado principalmente pela alternância no parâmetro formacional do movimento, entre e com os sinais. Ainda segundo Valli, existem quatro categorias de movimentos que podem ser alternados para a criação do ritmo nos poemas em língua de sinais: ênfase da pausa (pausa longa, pausa súbita ou pausa forte); ênfase do movimento (longo, curto, alterado ou repetido); tipo de movimento (trajetória alargada do movimento, movimento acelerado); e duração do movimento (regular, lento ou rápido).

Podemos concluir, então, que o ritmo em poemas em línguas de sinais vai depender das escolhas de como serão empregados e construídos os movimentos dos sinais do poema, bem como a alternância dos mesmos, sua duração, trajetória, ênfase e pausas. Essas escolhas darão ao poema sua entonação, bem como sua definição rítmica.

Ainda no que tange à camada fônica da poesia, segundo Goldstein (2005) podemos chamar de rima a repetição de sons semelhantes, que pode acontecer no interior de um mesmo verso ou no final de versos distintos, criando assim um parentesco fônico entre as palavras. Devemos considerar, então, que a rima está diretamente relacionada à questão do ritmo, "uma vez que o ritmo remete à regularidade, ou seja, a repetições dentro da estrutura do poema sujeitas a uma ordem" (KLAMT, 2014, p. 59).

Conforme Sutton-Spence (2005), as possibilidades de repetição dentro dos poemas em língua de sinais acontecem no nível

expressões não manuais (modificadores dos signos realizados pelas mãos, enfatizando a expressividade da mensagem).

Revista TextoPoético | ISSN: 1808-5385 | Vol. 21 (2o sem-2016) - p. 101. 
lexical da língua, composto pelos sinais (unidades semelhantes ao que se chamam palavras nas línguas orais), e no sublexical, composto pelos parâmetros formacionais da língua.

A repetição do léxico é por definição muito mais fácil de ser entendida: basta que encontremos no mesmo verso ou ainda na mesma estrofe ${ }^{23}$ sinais que se repetem, causando a rima inerente a todo processo iterativo. Já a rima no nível sublexical se dá pela repetição de um ou mais parâmetros na formação dos sinais no poema, como, por exemplo, a mesma configuração de mão, ou o mesmo ponto de articulação, ou o mesmo movimento. Nesse caso, "as rimas mais tênues ocorrem quando dois sinais compartilham os mesmos parâmetros inteiramente e somente o contexto os distingue" (QUADROS; SUTTON-SPENCE, 2006, p. 132).

Assim, quando temos o uso dos sinais AMAR (Figura 1) e GOSTAR (Figura 2), que só compartilham de um parâmetro formacional, o ponto de articulação, o efeito repetitivo é menor do que entre GOSTOSO e DELICIOSO (Figura 3), que compartilham a mesma configuração de mão, o ponto de articulação e a direção, sendo diferenciados apenas pela expressão facial usada pelo intérprete. Esses diferentes graus de similaridade entre os sinais implicam diferentes alternâncias e repetições de padrão, configurando a estrutura rítmica do poema.

${ }^{23}$ Por limitações de espaço inerentes a um artigo desta natureza, não discutiremos os conceitos de verso e estrofe em poemas nas línguas de sinais, limitando nossa reflexão aos fenômenos de ritmo e rima. Assim, para fins desta análise, tomaremos como versos as unidades sintático-semânticas do poema e como estrofes os conjuntos dessas unidades em torno de temáticas comuns.

Revista TextoPoético | ISSN: 1808-5385 | Vol. 21 (2o sem-2016) - p. 102. 


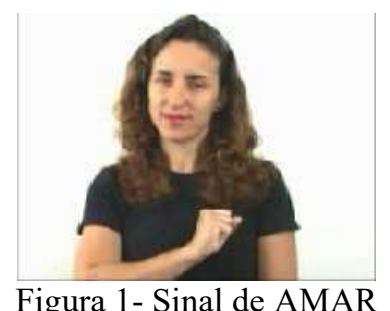

Fonte: Dicionário da Língua Brasileira de Sinais, 2008.

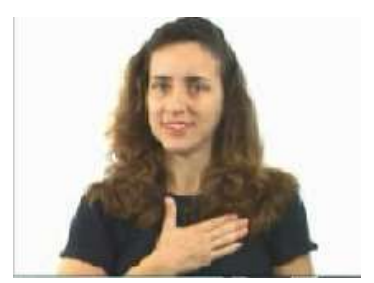

Figura 2- Sinal de GOSTAR

Fonte: Dicionário da Língua Brasileira de Sinais, 2008.

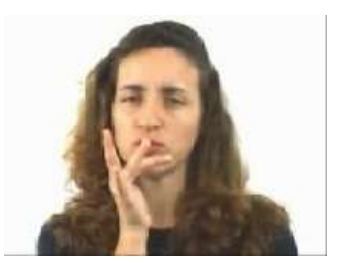

Figura 3- Sinal de GOSTOSO/ DELICIOSO

Fonte: Dicionário da Língua Brasileira de Sinais, 2008.

\section{Processos metodológicos}

A escolha do poema para análise neste artigo surgiu a partir de buscas na internet por poemas de Nelson Pimenta, um nome de Revista TextoPoético | ISSN: 1808-5385 | Vol. 21 (2o sem-2016) - p. 103. 
referência da literatura surda brasileira. Fizemos tal busca no ciberespaço porque, apesar de atualmente ser crescente o número de produções de poemas surdos no Brasil, a circulação dos mesmos ainda é marginalizada e se restringe quase exclusivamente a vídeos caseiros no Youtube e em blogs.

Em termos metodológicos, para que os elementos de construção do ritmo pudessem ser mais facilmente identificados no poema em nossa análise, especialmente num artigo publicado em língua escrita, e não de sinais, foram realizados os seguintes passos: a. leitura detalhada do poema gravado em vídeo; b. levantamento de sinais desconhecidos e verificação do léxico já conhecido; c. transcrição do poema - segundo os procedimentos de tradução livre e as regras de transcrição de Felipe (2001), com a criação de uma glosa para cada um dos sinais realizados no poema; e d. análise dos elementos de ritmo e rima no poema, a partir do vídeo e da glosa.

Cabe esclarecer que uma glosa é uma ferramenta de transcrição que auxilia na análise de textos em Libras, pois dá uma visão geral dos sinais utilizados, bem como permite uma aproximação do texto por parte de não falantes da Libras. O sistema de transcrição é feito através de notação de palavras em português em letras maiúsculas, que representam cada um dos sinais empregados no poema. Quando um sinal só puder ser traduzido por uma lexia de duas ou mais palavras em português, estas são unidas por hífen, como, por exemplo, em CORTAR-COM-FACA.

Além disso, algumas glosas podem conter o símbolo “@”, para indicar que, na Libras, os sinais não sofrem flexão de número ou gênero, o que implica glosas como AMIG@, EL@, MUIT@. Há também às vezes no poema a marcação do plural através da repetição 
de um mesmo sinal, o que é glosado com um sinal de adição, tal qual em ÁRVORE+.

Ademais, quando na realização de um sinal são empregados, juntamente com o sinal, traços não manuais, isto é, expressões faciais ou corporais, estas são representadas acima da glosa do sinal, indicando a ideia que estão acrescentando ao sinal, como, por exemplo, em frases interrogativas ou negativas.

\section{interrogativa \\ O QUE}

Há ainda a ocorrência de sinais que podem ser feitos apenas através de movimentos de cabeça, sem a utilização de um sinal com os parâmetros formacionais, como SIM e NÃO, os quais são transcritos entre colchetes.

Por fim, quando dois sinais são realizados simultaneamente, devemos indicar qual sinal está sendo realizado por qual das mãos, através das siglas md (mão direita) e me (mão esquerda).

Para melhor compreensão do texto poético analisado neste artigo, separamos as glosas em um quadro e tentamos agrupá-las de modo que construíssem uma significação do texto em geral, criando assim versos que facilitassem o entendimento do conteúdo do poema. Assim, as glosas foram agrupadas de três em três em cada linha numerada do quadro, para que pudéssemos tratar do que chamamos de versos do poema. No quadro, a primeira coluna referese ao tempo do vídeo em que o verso começa, a segunda refere-se ao número do verso, a terceira contém as glosas e a quarta define o tempo do vídeo em que o verso termina. Indicamos que o leitor, principalmente aquele que desconhece a Libras, acompanhe a glosa

Revista TextoPoético | ISSN: 1808-5385 | Vol. 21 (2o sem-2016) - p. 105. 
assistindo ao vídeo, para que assim possa ter uma melhor compreensão do poema e da análise aqui ensejada.

Para analisar o texto "Cinco Sentidos", foram consideradas neste artigo duas categorias que evidenciassem a formação do ritmo no poema: a repetição de sinais empregados no poema e as rimas produzidas pela repetição da configuração de mão. Em estudos futuros, pretendemos analisar outras categorias, visto que as rimas podem se formar não só através da repetição da configuração de mão, mas também da repetição da locação e do movimento.

Quadro 1: Transcrição do poema "Cinco sentidos"

00:12 1 Letra "A" (me) (o sinal da letra "A" 00:14 foi utilizado para representar uma porta, o que, na linguagem cotidiana em Libras, seria feito com a configuração de mão em B)

TOC-TOC (md) (o sinal de PORTA é realizado com a mão esquerda, enquanto a mão direita está fazendo o movimento de batida de porta na mão esquerda)

00:15 2 Polegar estendido e o restante dos $00: 16$ dedos fechados (me) (representando uma primeira pessoa abrindo a porta)

VOCÊ QUEM VOCÊ (md)

00:16 3 Polegar estendido e o restante dos 00:18 dedos fechados (me) (representando uma primeira pessoa a abrir a 
porta).

O QUE EU SER (md) (enquanto os sinais são feitos pela mão esquerda, a mão direita permanece parada, representando a primeira pessoa abrindo a porta)

00:18 4 Polegar estendido e o restante dos $00: 19$ dedos fechados (me) (representando uma primeira pessoa abrindo a porta).

VEM JUNTO CONHECER VEM (md) (o sinal de "junto" é realizado aqui apenas com uma mão, diferente do praticado na linguagem cotidiana em Libras, pois a outra mão permanece representando o sinal da primeira pessoa abrindo a porta)

$\begin{array}{llll}00: 19 & 5 & \text { VEM JUNTO VEM } & 00: 20 \\ 00: 20 & 6 & \text { MERGULHAR } & 00: 22 \\ 00: 22 & 7 & \text { PEGAR ABRAÇAR ARREPIAR } & 00: 24 \\ 00: 24 & 8 & \quad \text { Interjeição de surpresa } & 00: 25 \\ & & \text { SENTIR NOSSA } & \\ 00: 25 & 9 & \text { PEGAR PEGAR QUENTE } & 00: 30 \\ & & \text { QUEIMA } & \\ 00: 30 & 10 & \text { PEGAR FRIO GELO } & 00: 32 \\ 00: 32 & 11 & \text { MISTURAR MISTURAR } & 00: 34 \\ & & \text { MISTURAR } & \\ 00: 34 & 12 & \text { PEGAR PEGAR PEGAR PEGAR } & 00: 36 \\ 00: 36 & 13 & \text { MERGULHAR } & 00: 37 \\ 00: 37 & 14 & \text { [OK] AGORA CONHECER EU } & 00: 39 \\ 00: 39 & 15 & \text { [SIM] ENTENDER OBRIGAD@ } & 00: 41 \\ & & \text { (md) } & \end{array}$

Revista TextoPoético | ISSN: 1808-5385 | Vol. 21 (2o sem-2016) - p. 107. 


\begin{tabular}{|c|c|c|c|}
\hline & & $\begin{array}{l}\text { Polegar estendido e o restante dos } \\
\text { dedos fechados (me) (representando } \\
\text { uma primeira pessoa abrindo a porta) }\end{array}$ & \\
\hline \multirow[t]{2}{*}{$00: 41$} & 16 & Letra "A" (me) & $00: 44$ \\
\hline & & TOC-TOC (md) & \\
\hline \multirow[t]{2}{*}{$00: 44$} & 17 & $\begin{array}{l}\text { Dedo indicador estendido e o } \\
\text { restante dos dedos fechados (me) } \\
\text { (representando a segunda pessoa } \\
\text { abrindo a porta) }\end{array}$ & $00: 45$ \\
\hline & & VOCÊ QUEM VOCÊ (md) & \\
\hline $00: 45$ & 18 & QUEM EU VEM JUNTO & $00: 47$ \\
\hline $00: 47$ & 19 & OLHAR OLHAR OLHAR & $00: 49$ \\
\hline $00: 49$ & 20 & MERGULHAR & $00: 50$ \\
\hline \multirow[t]{3}{*}{$00: 50$} & 21 & EXPERIMENTAR & $00: 55$ \\
\hline & & EXPERIMENTAR & \\
\hline & & EXPERIMENTAR & \\
\hline $00: 55$ & 21 & PEGAR COMER COMER & $00: 59$ \\
\hline \multirow[t]{2}{*}{ 00:59 } & 22 & GOSTOS@GOSTOS@ & $1: 00$ \\
\hline & & GOSTOS@ & \\
\hline \multirow[t]{4}{*}{$1: 00$} & 23 & & $1: 05$ \\
\hline & & Interjeição de surpresa & \\
\hline & & EXPERIMENTAR COMER & \\
\hline & & NOSSA DELICIOS@ & \\
\hline 1:05 & 24 & COMER COMER COMER & $1: 06$ \\
\hline \multirow[t]{3}{*}{$1: 06$} & 25 & EXPERIMENTAR & $1: 08$ \\
\hline & & EXPERIMENTAR & \\
\hline & & EXPERIMENTAR & \\
\hline 1:08 & 26 & SALIVAR SALIVAR & $1: 10$ \\
\hline $1: 10$ & 27 & MERGULHAR & $1: 11$ \\
\hline $1: 11$ & 28 & EU CONHECER EU & $1: 13$ \\
\hline $1: 13$ & 29 & [SIM] ENTENDER OBRIGAD@ & $1: 15$ \\
\hline
\end{tabular}

Revista TextoPoético | ISSN: 1808-5385 | Vol. 21 (2o sem-2016) - p. 108. 
(md)

Dedo indicador estendido e o

restante dos dedos fechados (me)

(representando a segunda pessoa

abrindo a porta)

$1: 15 \quad 30$ Letra "A" (me)

TOC-TOC (md)

1:16 31 Dedo médio estendido e os demais $1: 17$ abaixados (me) (representando a terceira pessoa abrindo a porta)

VOCÊ QUEM VOCÊ (md)

1:17 32 Dedo médio estendido e os demais $1: 18$ abaixados (me)

O QUE SER (md) (enquanto os sinais são feitos pela mão esquerda, a mão direita permanece parada representando a primeira pessoa abrindo a porta)

$1: 1833$ OLHAR JUNTO VEM

1:20 34 MERGULHAR

Interjeição de surpresa

CHEIRAR CHEIRAR NOSSA CHEIRAR NOSSA

1:28 $36 \quad$ SENTIR-PERFUMEAGRADÁVEL ENTORPECID@

1:34 37 GOSTOS@GOSTOS@

CHEIRAR CHEIRAR PERFEIT@

1:37 38 CHEIRO PERFEIT@

1:38 39 MERGULHAR

$1: 40 \quad 40$ AGORA CONHECER EU (md) 1:41 
Dedo médio estendido e os demais abaixados (me) (representando a terceira pessoa abrindo a porta)

1:41 41 ENTENDER VOCÊ ENTENDER $1: 45$ OBRIGAD@(md)

Dedo médio estendido e os demais abaixados (me) (representando a terceira pessoa abrindo a porta)

1:45 $42 \quad$ Letra "A" (me)

TOC-TOC (md)

1:48 43 NADA ESTRANH@

1:51 44 [OK] PRÓXIMO (md)

Letra "A" (me)

1:52 45 Letra "A" (me)

TOC-TOC (md)

1:53 $46 \quad$ Dedo mínimo estendido e os

demais abaixados (me)

(representando quarta pessoa abrindo a porta)

interrogativa TUDO-BEM

1:55 $47 \quad$ interrogativa

O QUE ELE ACONTECER EU CHAMAR

1:56 48 VOCÊS-DOIS NINGUÉM O QUE 2:00

2:00 49 CALMA ENTÃO EU JUNTO 2:03 OLHAR PROCURAR NÓS-TRÊS JUNTO@

2:03 $50 \quad$ Interrogativa 2:05

Revista TextoPoético | ISSN: 1808-5385 | Vol. 21 (2o sem-2016) - p. 110. 
NÓS-TRÊS PODER

2:05 51 VEM MERGULHAR 2:07

2:07 52 ABRIR-OS-OLHOS ABRIR-OS- 2:09 OLHOS

2:09 53 PERCEBER PERCEBER

PERCEBER

$2: 11 \quad 54$

Interjeição de $\quad$ 2:14

surpresa

MUNDO PERCEBER PERCEBER PERCEBER NOSSA

$2: 14 \quad 55 \quad$ INFORMAÇÃO+ $\quad 2: 16$

2:16 56 PERCEBER PERCEBER 2:20 PERCEBER-PELOS-OLHOS

$2: 20 \quad 57$ MAR+ 2:22

$2: 22 \quad 58$ ÁRVORE+ 2:24

$2: 24 \quad 60$ COR COR ARCO-ÍRIS 2:27

2:27 61 CÉU PÁSSARO CÉU 2:32

2:32 62 CHUVA OLHAR CÉU MUNDO 2:39

$2: 3963$ MERGULHAR 2:41

2:41 64 AGORA CONHECER NÓS-DOIS 2:44 (md)

Dedos anelar e mínimo estendidos e os demais abaixados (me)

2:44 65 MARAVILHOS@ (md) 2:46

Dedos anelar e mínimo estendidos e os demais abaixados (me)

Fonte: transcrição feita pelos autores 


\section{Breve descrição do poema}

O vídeo do poema tem uma duração total de 02 minutos e 46 segundos. Ao que parece, foi gravado em um estúdio, com um fundo azul e com o intérprete vestido com uma camiseta preta, conforme protocolos frequentemente usados para interpretação em Libras. O vídeo não contém legendas, apenas o título do poema aparece no início da gravação, junto com o nome do autor do texto original e do tradutor para Libras.

O poema "Cinco sentidos" trata da experiência sensorial dos sujeitos surdos na descoberta do mundo que os cerca. Ao longo do poema, todos os sentidos são apresentados, com destaque para a visão; o poema menciona a falta da audição, mas não sob a perspectiva da perda de um sentido. Em vez disso, declara-se que a ausência da audição não compromete a experiência do mundo, compensada pelos demais sentidos. A ênfase não é em uma suposta deficiência ou incapacidade, e sim em uma sensorialidade diferenciada, haja vista o título trazer os cinco sentidos, e não quatro apenas.

Ao longo do poema, nota-se o que cada sentido do corpo proporciona ao sujeito do poema, que parece inicialmente desconhecer os sentidos, os quais the vão sendo apresentados ao longo do vídeo na seguinte ordem: tato, paladar, olfato, audição e visão. Cada sentido é representado no poema por um dos dedos da mão esquerda (do polegar ao mínimo), que, tocado pelo poeta, se levanta e apresenta ao sujeito o novo sentido a ser descoberto.

É interessante notar que o quarto dedo (anelar) não se levanta, remetendo ao sentido da audição. Se considerarmos a anatomia da mão, o fato de o dedo anelar nunca poder ser

Revista TextoPoético | ISSN: 1808-5385 | Vol. 21 (2o sem-2016) - p. 112. 
completamente levantado sem movimentar outro dedo torna ainda mais significativa a ideia de que os sujeitos surdos ressignificam a ausência de audição por meio de outras sensorialidades.

Assim, o quinto e último sentido, a visão, é apresentado juntamente com o sentido da audição, pois, só ao levantar o quinto dedo (o mínimo), pode o sujeito poético erguer o anelar. Isso indica que a falta do sentido da audição não interfere no entendimento de mundo que os surdos podem ter, pois o sentido da visão, desenvolvido de maneira diferente, supre a falta da audição. Notamos, então, a mistura de sentidos aqui através de uma sinestesia que se alonga na parte final do vídeo. Ao sentido da visão, dedicase um tempo maior no vídeo, como se percebe na glosa, nos segmentos de 46 a 63 . As experiências vivenciadas pelo sujeito por meio da visão, sobretudo junto à natureza, são descritas no poema com mais intensidade que as demais sensorialidades.

Note-se ainda que o vídeo conta com alguns elementos semióticos visuais que podem ser notados por leitores surdos e ouvintes e elementos sonoros que apenas leitores ouvintes podem captar. Entre os elementos visuais, destacam-se os jogos de iluminação no vídeo: sempre quando um dos sentidos é apresentado, o sujeito é levado a "mergulhar" no mundo daquele sentido, o que é marcado no vídeo pela troca da iluminação de uma cena para a outra. Além disso, no momento em que somos levados a "mergulhar", a tela do vídeo tem suas bordas escurecidas, pelo efeito vignetting.

Quanto aos elementos sonoros, apesar de não termos a voz do poeta na interpretação, há outros sons produzidos por ele, tais como sopros, ruídos de degustação, estalos com a boca, barulho de respiração; além disso, enquanto o poeta se movimenta durante a performance, podemos observar um barulho que acompanha seu

Revista TextoPoético | ISSN: 1808-5385 | Vol. 21 (2o sem-2016) - p. 113. 
movimento. Como tais elementos sonoros poderiam ter sido facilmente retirados do vídeo por meio de qualquer programa de edição (prática constante em outros vídeos em Libras), torna-se intencional (e, portanto, significativa) a escolha por mantê-los, o que proporciona inputs sensoriais distintos (e também interpretações diferentes) para os públicos surdo e ouvinte.

Análise dos aspectos de ritmo e rima no poema "Cinco sentidos"

No poema "Cinco sentidos", podemos encontrar várias repetições, tanto no nível lexical quanto no sublexical. No primeiro, destaca-se a repetição de 16 sinais ao longo de todo o poema, como pode ser visto na tabela abaixo. Tais repetições acontecem em toda a extensão do poema, ora em um mesmo verso e/ou estrofe, ou ainda em versos e estrofes diferentes.

Quadro 2: repetições de sinais no poema

\begin{tabular}{|l|c|}
\hline \multicolumn{1}{|c|}{ Sinal } & Número de repetições \\
\hline MERGULHAR & 7 \\
\hline PEGAR & 9 \\
\hline MISTURAR & 3 \\
\hline EXPERIMENTAR & 7 \\
\hline COMER & 6 \\
\hline GOSTOS@ & 5 \\
\hline NOSSA & 3 \\
\hline
\end{tabular}

Revista TextoPoético | ISSN: 1808-5385 | Vol. 21 (2o sem-2016) - p. 114. 


\begin{tabular}{|l|c|}
\hline \multicolumn{1}{|c|}{ Sinal } & Número de repetições \\
\hline SALIVAR & 2 \\
\hline CHEIRAR & 5 \\
\hline PERFEITO & 2 \\
\hline ABRIR-OS-OLHOS & 2 \\
\hline PERCEBER & 9 \\
\hline MAR & 2 \\
\hline ÁRVORE & 2 \\
\hline COR & 2 \\
\hline CÉU & 3 \\
\hline MUNDO & 2 \\
\hline
\end{tabular}

Fonte: Elaboração dos autores

A repetição do sinal MERGULHAR, usado a cada vez que um dos cinco sentidos é apresentado, dá ao poema forte impacto visual e rítmico, uma vez que reiteradamente convida o leitor a mergulhar no poema e nas sensações que este descreve, recontextualizando o sujeito surdo diante do mundo que apreende em suas particularidades perceptivas.

Já a repetição dos sinais PEGAR, MISTURAR, EXPERIMENTAR, GOSTOS@, CHEIRAR, SALIVAR, ABRIROS-OLHOS e PERCEBER nos remete imediatamente aos sentidos do corpo humano explorados no texto, enfatizando a ideia de sistemática e constante imersão no mundo perceptivo. Note-se, neste

Revista TextoPoético | ISSN: 1808-5385 | Vol. 21 (2o sem-2016) - p. 115. 
momento, que também o ritmo é uma dimensão do texto poético apreendida pelos sentidos, seja na audição da voz lírica ou na visão do sinal compassado. Ademais, a cadeia rítmica garante a continuidade e progressão no poema, alinhavando as diferentes sensações evocadas pelo poeta como um todo perceptivo.

Por fim, a repetição dos sinais MAR, CÉU, ÁRVORE, COR e MUNDO enfatiza os elementos da natureza que podem ser vistos e vivenciados através do sentido da visão, notoriamente destacado entre os sujeitos surdos, ressaltando as dimensões do real enquanto objeto de que se apropria o sujeito surdo em suas particularidades fenomenológicas.

É importante ressaltar que, na seleção de sinais que se repetem ao longo do poema, não foram incluídos na tabela aqueles que se reiteram no que aqui estamos considerando o refrão do poema. Adotamos tal nomenclatura, cara à poesia de línguas orais, já que se trata em "Cinco Sentidos" também de frases e estruturas gramaticais responsáveis pela abertura e finalização das ideias em cada estrofe, como analisaremos adiante.

O refrão pode ser percebido na glosa, nos versos de 1-5/1415/16-19/28-29/30-34/40-41/42-51/64-65. Segundo Sutton-Spence (2005), a utilização de refrãos é pouco utilizada em poemas em língua de sinais, mas pode acontecer através da repetição de frases que introduzem um novo tema em uma nova estrofe.

Em "Cinco sentidos", repete-se, na condição de refrão, uma apresentação do sentido ao sujeito lírico no início de cada estrofe, sugerindo a falta de conhecimento dos sujeitos surdos quanto a algumas experiências sensoriais. Por outro lado, ao final das estrofes há outra construção com características de refrão, na qual se dá um

Revista TextoPoético | ISSN: 1808-5385 | Vol. 21 (2o sem-2016) - p. 116. 
agradecimento do sujeito lírico depois de ter entendido que cada sentido lhe fornece oportunidades até então desconhecidas.

Em termos estilísticos, observa-se ainda que, repetindo um traço morfofonêmico do sinal, o poema atinge efeitos de expressão e conteúdo que talvez possam ser lidos à luz da estilística fônica (ou fonoestilística). A esse respeito, Martins (2008) afirma que os prosodemas $^{24}$ constituem um complexo sonoro importantíssimo para as funções emotivas e poéticas.

Os sons da língua - como outros sons dos seres - podem provocar-nos uma sensação de agrado ou desagrado e ainda sugerir ideias, impressões. O modo como o locutor profere as palavras da língua pode também denunciar estados de espirito ou traços de personalidade. (...) São os artistas que trabalham com a palavra, poetas e atores, os que melhor apreendem o potencial de expressividade dos sons e que deles extraem um uso mais refinado. (MARTINS, 2008, p. 26)

Transpondo essa ideia para as línguas de sinais, Sutton-Spence (2005) afirma que a repetição de configurações de mãos (Figura 4) abertas possibilita a criação de imagens positivas e alegres, ao passo que configurações de mãos fechadas criam imagens tensas ou negativas.

${ }^{24}$ Aspectos suprassegmentais, como os acentos, a entonação e o ritmo.

Revista TextoPoético | ISSN: 1808-5385 | Vol. 21 (2o sem-2016) - p. 117. 


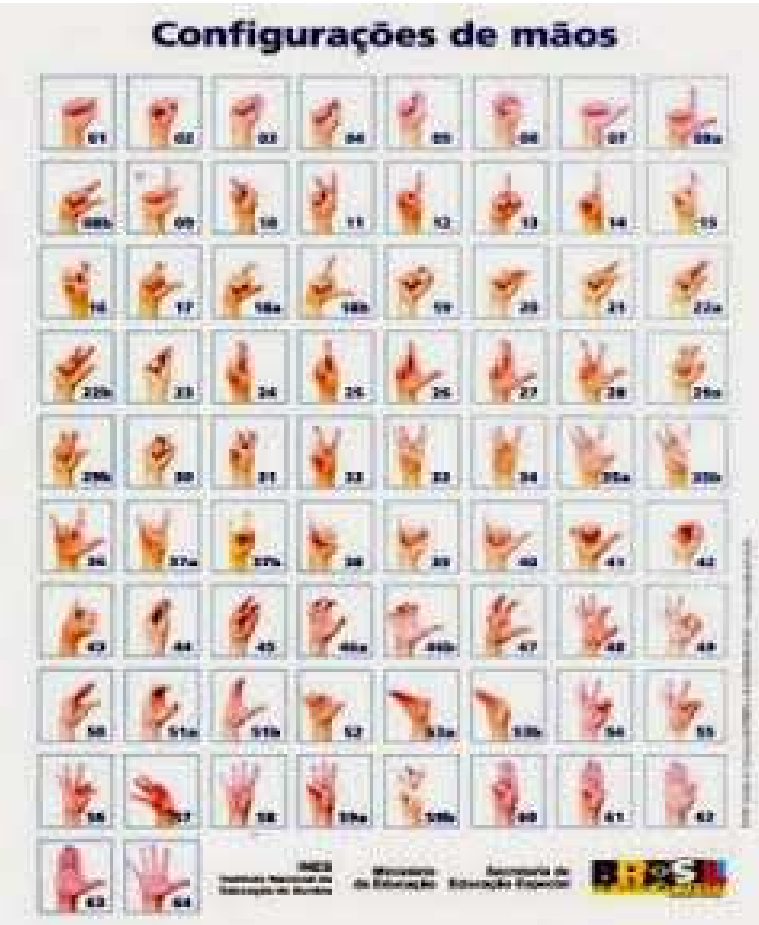

Figura 4 - Configurações de mão em Libras.

Fonte - Instituto Nacional de Educação dos Surdos, n. d.

Sendo assim, no poema temos sinais que se repetem quanto à sua configuração de mão totalmente aberta: VEM, CONHECER, MERGULHAR, NOSSA, AGORA, ENTENDER, EU, OBRIGAD@, SENTIR-PERFUME-AGRADÁVEL, ENTORPECID@, ACONTECER, CALMA, ENTÃO, MUNDO, MAR, ÁVORE, COR, CÉU, CHUVA, PÁSSARO, MARAVILHOS@.

Os sinais que têm a configuração de mão semiaberta são: VOCÊ, O QUE, SER, SENTIR, QUENTE, QUEIMA, FRIO, GELA, OK, OLHAR, EXPERIMENTAR, COMER, GOSTOS@,

Revista TextoPoético | ISSN: 1808-5385 | Vol. 21 (2o sem-2016) - p. 118. 
INFORMAÇÃO, EU, DELICIOS@, SALIVAR, PERFEIT@, NADA, ESTRANH@, PERCEBER, PRÓXIM@,PROCURAR.

Por sua vez, os sinais com a configuração de mão fechada são “A”, TOC-TOC, JUNTO, ABRAÇAR, MISTURAR, PODER.

Por último, temos os sinais, que, pela movimentação interna do sinal, começam fechados e terminam abertos: ARREPIAR, TUDOBEM, ABRIR-OS-OLHOS. E, ainda, os sinais que iniciam abertos e fecham-se: PEGAR, CHEIRAR e CHAMAR.

Com base nessa breve análise estilística da escolha dos sinais quanto à configuração de mão no poema, podemos concluir que o nível fônico reforça a positividade da experiência sensorial a que se lança o sujeito, na medida em que sinais com configuração de mão aberta ou semiaberta são bem mais numerosos no poema. Não se trata, pois, de uma suposta queixa sobre a falta de um dos sentidos no nível do conteúdo; ao contrário, ressalta-se no poema a ideia de que a surdez não é falta na percepção de mundo, e sim uma positividade.

Ademais, em termos de variações estilísticas, notamos que o sinal indicativo de EU aparece em momentos distintos do poema com diferentes configurações de mão, ora aberta e ora semiaberta (Figura 5).

A mesma coisa acontece com o sinal CONHECER, que pode ser feito com a palma da mão aberta ou com a configuração de mão em B. A escolha do poeta por uma ou outra configuração garante a rima com os sinais adjacentes. São sinais que compõem o último verso do refrão: AGORA, CONHECER, EU, ENTENDER, OBRIGAD@ (Figura 6).

Revista TextoPoético | ISSN: 1808-5385 | Vol. 21 (2o sem-2016) - p. 119. 


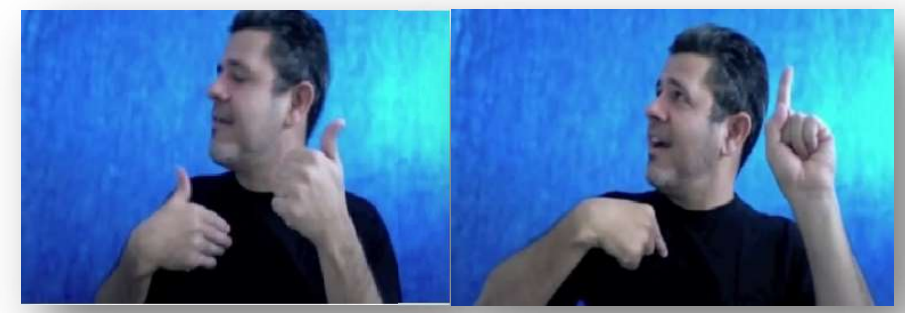

Figura 5: Diferentes usos do sinal EU Fonte: SCOTT, 2009

\section{AGORA CONHECER EU \\ ENTENDER OBRIGAD@}

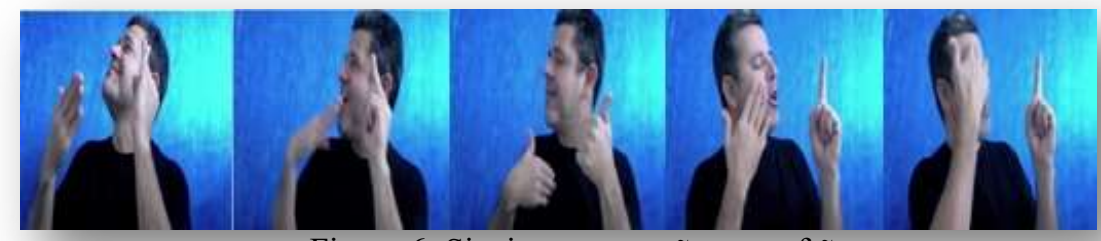

Figura 6: Sinais que compõem o refrão

Fonte: SCOTT, 2009

\section{Considerações finais}

É fundamental, antes de mais nada, reconhecermos que as formas líricas já canonizadas pelos estudos de teorias literárias não abarcam todas as manifestações poéticas que existem hoje nas mais diversas línguas. A nossa sociedade, língua e meios de manifestações culturais mudam, incorporando, progressivamente, as manifestações artístico-literárias de diferentes grupos culturais. Nesse contexto, precisamos assumir e investigar a diversidade linguística e poética inerente a essas novas formas poéticas - o que,

Revista TextoPoético | ISSN: 1808-5385 | Vol. 21 (2o sem-2016) - p. 120. 
no que tange a este artigo, implica pensar a poesia produzida em língua de sinais. Nesse sentido, talvez se faça necessário ampliar o conceito de poema, para além de sua quase universal associação com o som. O que a camada fônica dos poemas em Libras revela é que fenômenos como rima e ritmo podem se dar na visualidade do poema - em alguma medida ampliando o escopo de discussões do grupo concretista para línguas não orais.

Sabemos que ainda há muito a ser estudado e descoberto sobre a poesia em línguas de sinais, porém já podemos notar que há uma estrutura formal-estilística presente nessas obras que não pode ser ignorada e que há muito mais a ser visto do que aspectos temáticos desses textos. Devemos, portanto, voltar cada vez mais nosso olhar para a linguagem, que é a figura chave da poética contemporânea, "não a linguagem que diz, ou que precisa dizer alguma coisa, mas uma linguagem que parece cada vez mais se desdobrar sobre si mesma" (BYLAARDT, 2012, p. 231).

A partir deste estudo, pudemos evidenciar que, assim como nas línguas orais-auditivas, os poemas em língua de sinais contêm elementos na base de sua formação há muito já estudados e discutidos na tradição literária das línguas orais-auditivas, ainda que estes se manifestem de modo distinto em línguas visuo-gestuais. Assim, discutimos, ainda que inicialmente, o conceito de ritmo e rima nas produções realizadas em Libras. Percebemos que tais fenômenos se fazem presentes nessas obras, através dos parâmetros constituintes dos sinais em Libras, e que é através da alternância dos movimentos e da repetição de um ou mais parâmetros formacionais que tais estruturas fônicas se manifestam nos poemas sinalizados.

Revista TextoPoético | ISSN: 1808-5385 | Vol. 21 (2o sem-2016) - p. 121. 


\section{Referências}

BARTHES, R. Aula. São Paulo: Cultrix, 1977.

BRIK, O. Ritmo e sintaxe. In: EIKHENBAUM et alii. Teoria da literatura: formalistas russos. Porto Alegre: Globo, 1979.

BRITO, L. F. Por uma gramática de língua de sinais. Rio de Janeiro: Tempo Brasileiro, 2010.

BYLAARDT, C. O. A estética contemporânea: nova poética, novo olhar. Estudos de literatura brasileira contemporânea. Brasília, n. 39, p. 215233, jan./jun. 2012.

DICIONÁRIO DA LÍNGUA BRASILEIRA DE SINAIS. 2008. Disponível em: <https://www.acessibilidadebrasil.org.br/libras/>. Acesso em: $02 \mathrm{dez}$ 2015.

FELIPE, T. A. 2001. LIBRAS em contexto: curso básico. Livro do estudante. Brasília, Ministério da Educação/Secretaria de Educação Especial.

GOLDSTEIN, N. Versos, Sons, Ritmos. 13. ed. São Paulo: Ática, 2005. (Série Princípios)

INSTITUTO NACIONAL DE EDUCAÇÃO DE SURDOS. n. d. Disponível em: <http://ines.gov.br/index.php>. Acesso em: 02 dez. 2015.

KLAMT, M. M. O ritmo na poesia em Língua de Sinais. Florianópolis, 2014. Dissertação de mestrado - Programa de Pós-Graduação em Linguística. Universidade Federal de Santa Catarina. Florianópolis, 2014.

MARTINS, N. S. Introdução à Estilística: A expressividade na Língua Portuguesa. 4. ed. rev. São Paulo: Editora da Universidade de São Paulo, 2008.

PAZ, O. Poesia e poema. In: O arco e a lira. 2. ed. Rio de Janeiro: Nova Fronteira, 1982.

Revista TextoPoético | ISSN: 1808-5385 | Vol. 21 (2o sem-2016) - p. 122. 
SCOTT, P. Cinco sentidos. Trad. de Nelson Pimenta. 2009. Disponível em: $<$ https://www.youtube.com/watch?v=xmOnY1B2jEI $>$. Acesso em: $02 \mathrm{dez}$ 2015.

PORTO, S. B. Análise de poesias em língua de sinais. In: Estudos Surdos: diferentes olhares. Porto Alegre: Mediação, 2011.

QUADROS, R.; KARNOPP, L. B. Língua de Sinais brasileira: estudos linguísticos. Porto Alegre: Artmed, 2004.

QUADROS, R. M. de; SUTTON-SPENCE, R. Poesia em língua de sinais: traços da identidade surda. In: QUADROS, R. M. de. Estudos Surdos I. Petrópolis, RJ: Editora Arara Azul, 2006.

ROSA, F. S. Literatura, Letramento e Práticas educacionais - Grupo de Estudos Surdos Educação. Campinas, SP: Educação temática digital, 2006.

ROSA, O. M.; CAMARGO, G. O. de. A performance da voz e a subjetividade na poesia contemporânea. Outra Travessia, Santa Catarina, n. 15, p. 205-225, 2013.

SUTTON-SPENCE, R.; LADD, P.; RUDD, G. Analysing Sign Language Poetry. 1. ed. New York: Palgrave Macmillan, 2005.

Aprovado em 17 de maio de 2016.

Revista TextoPoético | ISSN: 1808-5385 | Vol. 21 (2o sem-2016) - p. 123. 